\title{
Mechanisms by Which Saturated Triacylglycerols Elevate the Plasma Low Density Lipoprotein-Cholesterol Concentration in Hamsters \\ Differential Effects of Fatty Acid Chain Length
}

\author{
Laura A. Woollett, David K. Spady, and John M. Dietschy \\ Department of Internal Medicine, University of Texas Southwestern Medical Center at Dallas, Dallas, Texas 752358887
}

\begin{abstract}
These studies were designed to elucidate how shorter (MCT) and longer (HCO) chain-length saturated triacylglycerols and cholesterol interact to alter steady-state plasma LDL-cholesterol levels. When either MCT or HCO was fed in the absence of cholesterol, there was little effect on receptor-dependent LDL transport but a 36-43\% increase in LDL-cholesterol production. Cholesterol feeding in the absence of triacylglycerol led to significant suppression of receptor-dependent LDL transport and a 26-31\% increase in LDL-cholesterol production. However, when the longer chain-length saturated triacylglycerol was fed together with cholesterol there was a marked increase in the suppression of receptor-dependent LDL transport and an $82 \%$ increase in production rate. Together, these two alterations accounted for the observed eightfold increase in plasma LDL-cholesterol concentration. In contrast, feeding the shorter chain-length saturated triacylglycerol with cholesterol actually enhanced receptor-dependent LDL transport while also causing a smaller increase (52\%) in the LDL-cholesterol production rate. As a result of these two opposing events, MCT feeding had essentially no net effect on plasma LDL-cholesterol levels beyond that induced by cholesterol feeding alone.
\end{abstract}

\section{Introduction}

In the steady state, the concentration of cholesterol carried in the low density lipoprotein (LDL) fraction is determined by the rate of entry of LDL into the vascular space and by the rate of LDL removal from the plasma by the different transport processes located in the various tissues of the body (1-4). These transport processes are now known to be of two types. The first is mediated by the $\mathrm{LDL}$ receptor mechanism $(5,6)$ and, therefore, manifests saturation kinetics in the live animal (7). The second process is receptor independent (8) so that the rate of LDL uptake into tissues by this mechanism is a linear function of the plasma LDL-cholesterol concentration (9). Thus, in more specific terms, the concentration of LDL-cholesterol in plasma is dictated by four separate variables: $(a)$ the

\footnotetext{
Address reprint requests to Dr. Woollett, Division of Gastroenterology, Department of Internal Medicine, University of Texas Southwestern Medical Center, 5323 Harry Hines Boulevard, Dallas, TX 75235 8887.

Received for publication 1 December 1988 and in revised form 24 January 1989.
}

J. Clin. Invest.

(c) The American Society for Clinical Investigation, Inc.

$0021-9738 / 89 / 07 / 0119 / 10 \quad \$ 2.00$

Volume 84, July 1989, 119-128 rate at which LDL-cholesterol is produced and enters the plasma space $\left(\mathrm{J}_{\mathrm{t}}\right) ;{ }^{1}(b)$ the maximal achievable rate of receptor-dependent uptake in the whole animal $\left(* J^{\mathrm{m}}\right) ;(c)$ the concentration of plasma LDL-cholesterol necessary to achieve half of this maximal transport rate $\left(* K_{\mathrm{m}}\right)$; and $(d)$ the rate of receptor-independent transport by the various organs $(* P)$. At any plasma $\mathrm{LDL}$ concentration the rate of $\mathrm{LDL}$ production $\left(J_{t}\right)$ must equal the sum of the rates of removal by the receptor-dependent $\left(J_{d}\right)$ and receptor-independent $\left(J_{i}\right)$ processes.

In most experimental animals on a low-cholesterol, lowtriacylglycerol diet such as the rat, hamster, and rabbit, $\sim 71-75 \%$ of the LDL that is removed from the plasma is transported out by the receptor-dependent process (10-12). Since in these, and other species the vast majority of such receptor-dependent transport activity is located in the liver, it follows that in this situation the liver is the major site for LDL uptake and degradation $(9,10,12,13)$. However, when such receptor activity is suppressed or absent, either because of environmental or genetic reasons, the receptor-independent process becomes quantitatively more important and the extrahepatic tissues become a major, or even predominant site for LDL uptake and degradation (12). The same series of events occurs in any physiological situation where there is relative overproduction of LDL-cholesterol, even though total receptor activity remains constant. With overproduction there is greater saturation of the receptor-dependent process and a shift in the burden LDL clearance to the receptor-independent transport process.

Of the four variables known to influence the plasma LDLcholesterol concentration and sites of LDL degradation, clearly the two most powerful are the rates of LDL-cholesterol production $\left(J_{t}\right)$ and the level of receptor activity $\left(* J^{\mathrm{m}}\right)$ found in the whole animal $(2,3)$. Furthermore, there are now several lines of evidence suggesting that the progressive rise in the concentration of LDL-cholesterol seen in man with aging is primarily the result of changes in these two variables, i.e., a progressive increase in LDL production and a progressive loss of whole-body receptor-dependent LDL transport activity (14-17). However, it is not clear whether these changes are attributable to aging per se or, alternatively, are due to some environmental factor such as the cholesterol and triacylglycerol content of the typical Western diet (17).

1. Abbreviations used in this paper: $\mathrm{HCO}$, hydrogenated coconut oil; $* J^{\mathrm{m}}$, the maximal achievable rate of receptor-dependent LDL transport in an organ or the whole animal; $J_{t}$, the total rate of LDL uptake into a particular tissue or into all tissues of the whole animal by both receptor-dependent $\left(J_{\mathrm{d}}\right)$ and receptor-independent $\left(J_{\mathrm{i}}\right)$ transport; $* K_{\mathrm{m}}$, the concentration of plasma LDL-cholesterol necessary to achieve half the velocity of $* J^{\mathrm{m}}$; MCT, medium chain-length triacylglyceride; $* \mathrm{P}$, the proportionality constant for receptor-independent LDL transport in an organ or the whole animal. 
There is little doubt, however, that these dietary components can alter some aspects of LDL metabolism. Cholesterol feeding, for example, causes modest suppression of hepatic receptor-dependent LDL transport and increases the plasma LDL-cholesterol concentration $(18,19)$. This effect is markedly influenced, however, by the amount and type of triacylglycerol also present in the diet. Triacylglycerols containing saturated longer chain-length fatty acids, for example, markedly augment the suppressive effect of dietary cholesterol on hepatic LDL receptor activity while triacylglycerols that contain mono- or polyunsaturated fatty acids tend to reverse this suppressive effect and increase receptor-dependent LDL uptake into the liver $(19,20)$. However, early in the time course of such feeding experiments, the plasma LDL-cholesterol concentration may increase significantly before any change in hepatic receptor activity is observed (19). Furthermore, the marked increase in plasma LDL-cholesterol levels seen with the feeding of cholesterol and saturated fatty acids is far in excess of that anticipated from the additional suppressive effect of these lipids on hepatic receptor activity (20). Thus, while there is little doubt that both dietary cholesterol and triacylglycerol significantly influence the rates of LDL uptake by the liver, the quantitative relationships between plasma LDL-cholesterol levels and LDL-cholesterol production and transport in the whole animal are still poorly understood. The present studies were undertaken, therefore, to better define the quantitative aspects of these processes that regulate plasma LDL-cholesterol levels under circumstances where the animals were fed cholesterol in combination with either longer or shorter chain-length triacylglycerols.

\section{Methods}

Animals and diets. Male Golden Syrian hamsters (Charles River Lakeview, New Field, NJ) were housed in colony cages and subjected daily to $12 \mathrm{~h}$ of light and $12 \mathrm{~h}$ of dark for 1-2 wk before use and throughout the experiments. The control diet used in these experiments was ground Wayne Lab Blox (Allied Mills, Chicago, IL) containing $0.23 \mathrm{mg} / \mathrm{g}$ of cholesterol and $50 \mathrm{mg} / \mathrm{g}$ of total fat. The fatty acid composition of the control diet is presented elsewhere (20). In some experiments cholesterol was added to the diets at concentrations of $0.06 \%$ and $0.12 \%$ (wt/wt), which corresponds to $0.6 \mathrm{mg}$ and $1.2 \mathrm{mg}$ of added cholesterol per gram of food. These concentrations were verified by gas-liquid chromatography after extraction of the sterols from the diets. Cholesterol was added to the diets in either warm ethanol, which was later evaporated, or warm oil, and the diets were then mixed in a mechanical food blender. Triacylglycerol was added to the diets at a concentration of $20 \%(\mathrm{wt} / \mathrm{wt})$ so that $20 \mathrm{~g}$ of the lipid was mixed with $80 \mathrm{~g}$ of the ground chow. The fatty acid profiles of the triacylglycerols used in these studies were analyzed by gas-liquid chromatography as methyl ester derivatives of the fatty acids. The fatty acid composition of the medium-chain length triglycerides (MCT) (Mead Johnson \& Co., Evansville, IN) was $77 \%$ as the $8: 0$ fatty acid and $23 \%$ as the $10: 0$ fatty acid. The hydrogenated coconut oil (HCO) contained $11 \%, 7 \%$, $50 \%, 16 \%, 7 \%$, and $9 \%$ as the $8: 0,10: 0,12: 0,14: 0,16: 0$, and 18:0 fatty acids, respectively. Diets were fed ad lib. and experiments were carried out during the mid-dark phase of the light cycle.

Analytical procedures. Plasma LDL-cholesterol and HDL-cholesterol concentrations were determined by simultaneously centrifuging the plasma at densities of 1.020 and $1.063 \mathrm{~g} / \mathrm{ml}$. Cholesterol content of total plasma and the top and bottom fractions of each tube was assayed colorimetrically (21). Free and esterified hepatic cholesterol were separated on silicic acid/celite columns (22), saponified and quantitated using gas-liquid chromatography. The content of these tissue sterols was expressed as the $\mathrm{mg}$ of cholesterol per $\mathrm{g}$ wet weight $(\mathrm{mg} / \mathrm{g})$.
In vivo hepatic sterol synthesis. Animals were killed by exsanguination through the abdominal aorta $1 \mathrm{~h}$ after the intravenous administration of $\left[{ }^{3} \mathrm{H}\right]$ water $(100 \mathrm{mCi})(23,24)$. Liver samples were then taken for isolation of digitonin precipitable sterols as previously described (25). The rates of sterol synthesis were expressed as the nmol of $\left[{ }^{3} \mathrm{H}\right]$ water incorporated into digitonin precipitable sterols per $\mathrm{h}$ per $\mathrm{g}$ of liver (nmol/h per $\mathrm{g}$ ).

Lipoprotein preparations. Hamster LDL was isolated in the density range of $1.020-1.055 \mathrm{~g} / \mathrm{ml}$ by preparative ultracentrifugation. The donor animals had been maintained on a low-cholesterol, low-fat control diet before harvesting the blood. Lipoproteins were labeled with either [ $\left.{ }^{125} I\right]$ tyramine cellobiose (26) or ${ }^{131} I$ (27). Lipoproteins were used within $24 \mathrm{~h}$ of preparation and were filtered through a $0.45-\mu \mathrm{m}$ Millipore filter immediately before use.

In vivo $L D L$ clearance rates. Rates of tissue $L D L$ clearance were determined in vivo using a primed-continuous infusion of $\left[{ }^{125} I\right]$ tyramine cellobiose-labeled $\operatorname{LDL}(7,13)$. In order to maintain a constant specific activity in the plasma, the radiolabeled LDL in the priming dose was kept constant while the amount of radiolabeled LDL infused each $\mathrm{h}$ varied in each dietary group. $10 \mathrm{~min}$ before termination of the 4-h infusion period, a bolus of ${ }^{131}$ I-labeled LDL was administered to each of the animals. The animals were then killed at $4 \mathrm{~h}$ by exsanguination through the abdominal aorta. Liver, small intestine, adrenal glands, spleen, and kidneys were excised, rinsed, and weighed. Aliquots of the liver and plasma, and the whole small intestine, adrenal glands, spleen, and kidneys were assayed for radioactivity. The remaining carcass was frozen in liquid nitrogen and ground to a fine powder. Aliquots were then assayed for radioactivity. Clearance rates were determined by subtracting the tissue space of $L D L$ at $10 \mathrm{~min}\left({ }^{131} \mathrm{I} \mathrm{dpm}\right.$ per $\mathrm{g}$ of tissue divided by the ${ }^{131} \mathrm{I} \mathrm{dpm}$ per $\mu \mathrm{l}$ of plasma) from the tissue space of LDL at $4 \mathrm{~h}$ ( ${ }^{125} \mathrm{I} \mathrm{dpm}$ per $\mathrm{g}$ of tissue divided by the ${ }^{125} \mathrm{I} \mathrm{dpm}$ per $\mu \mathrm{l}$ of plasma). These clearance rates were presented as the microliters of plasma cleared of its LDL content per hour per gram of tissue $(\mu \mathrm{l} / \mathrm{h}$ per g). In addition, these rates were multiplied by whole tissue weights in order to calculate the rates of LDL clearance by the whole organs $(\mu \mathrm{l} / \mathrm{h}$ per tissue).

In vivo $L D L$-cholesterol uptake rates. From these $\mathrm{LDL}$ clearance rates, uptake rates of LDL-cholesterol were determined. These uptake rates were expressed as the absolute mass of LDL-cholesterol that was taken up per $\mathrm{h}$ per $\mathrm{g}$ of tissue $(\mu \mathrm{g} / \mathrm{h}$ per $\mathrm{g})$ and were calculated by multiplying the clearance rates of $\operatorname{LDL}(\mu \mathrm{l} / \mathrm{h}$ per $\mathrm{g})$ by the plasma LDL-cholesterol concentration $(\mu \mathrm{g} / \mu \mathrm{l})$. These rates, in turn, were multiplied by whole tissue weights to give the LDL-cholesterol uptake rates per whole tissue ( $\mu \mathrm{g} / \mathrm{h}$ per tissue).

In vivo LDL-cholesterol production rates. Because these studies were performed during steady-state conditions where there was no detectable change in the plasma LDL-cholesterol concentration, the sum of the LDL-cholesterol uptake rates in all of the tissues of the animal must equal the rate of LDL-cholesterol production. Thus, LDL-cholesterol production rates were calculated by summing the LDL-cholesterol uptake rates in all tissues of the animal, including the residual carcass, and these values were expressed as the $\mu \mathrm{g}$ of LDLcholesterol produced per $\mathrm{h}$ per whole animal ( $\mathrm{g} / \mathrm{h}$ per animal).

Calculations. The steady state concentration of LDL-cholesterol is known to be determined by four separate parameters of LDL metabolism $(2,3,7)$. The rate at which LDL-cholesterol is taken up by a particular organ or by all of the tissues of the body $\left(J_{t}\right)$ is equal to the sum of the rates of uptake by the receptor-dependent $\left(J_{d}\right)$ and receptor-independent $\left(J_{i}\right)$ transport processes in that organ or whole animal (7). Since $J_{\mathrm{d}}$ equals $\left(* J^{\mathrm{m}} \mathrm{C}_{1}\right) /\left(* K_{\mathrm{m}}+\mathrm{C}_{1}\right)$ and $J_{\mathrm{i}}$ equals $* \mathrm{PC}$, it follows that $J_{t}$ for any organ or for the whole animal can be calculated from the following expression (2):

$J_{\mathrm{t}}=\frac{* J^{\mathrm{m}} \mathrm{C}_{1}+* \mathrm{PC}_{1} * K_{\mathrm{m}}+* \mathrm{PC}_{1}^{2}}{* K_{\mathrm{m}}+\mathrm{C}_{1}}$

The parameter $* J^{\mathrm{m}}$ is the maximal receptor-dependent transport velocity (a reflection of receptor number); $* K_{\mathrm{m}}$ is the plasma concentra- 
tion of LDL-cholesterol at which one-half of this maximal transport rate is achieved (a reflection of receptor affinity); $C_{1}$ is the concentration of plasma LDL-cholesterol in a given animal; and $* \mathrm{P}$ is the proportionality constant for LDL transport by way of the receptor-independent pathway. The relationship between $J_{t}$ and $C_{1}$ can be defined for a particular organ like the liver (e.g., as shown in Fig. 2) or for the whole animal (e.g., as shown in Fig. 3). Furthermore, in this latter case, this equation can be rearranged to give an expression that defines how the plasma LDL-cholesterol concentration $\left(C_{1}\right)$ will change in the whole animal given any alteration in receptor number $\left(* J^{\mathrm{m}}\right)$ or LDLcholesterol production since, in the steady-state, the rate of LDL-cholesterol removal from the plasma space $\left(J_{t}\right)$ must equal the rate of entry into the plasma. This second expression is as follows:

$\mathrm{C}_{1}=\frac{\left(J_{\mathrm{t}}-* J^{\mathrm{m}}-* \mathrm{P} * K_{\mathrm{m}}\right)+\sqrt{\left(J_{\mathrm{t}}-* J^{\mathrm{m}}-* \mathrm{P} * K_{\mathrm{m}}\right)^{2}+4 * \mathrm{P} * K_{\mathrm{m}} J_{\mathrm{t}}}}{2 * \mathrm{P}}$

The specific values for each of these parameters in the liver and the whole animal were determined in each appropriate control group of hamsters and are given in the text (4). In each experiment, changes in receptor number $\left(* J^{\mathrm{m}}\right)$ and production rate $\left(J_{t}\right)$ are given relative to the absolute values for these two parameters experimentally determined in the appropriate control animals (e.g., as given in Table III).

Where appropriate, mean values \pm 1 SEM are given. The factorial design was statistically analyzed for main effects and interactions of cholesterol and triacylglycerol by using analysis of variance $(P<0.05)$ (28). Student's $t$ tests were used at the $P<0.01$ level to make comparisons between levels of cholesterol or types of triacylglycerol when a significant interaction of $P<0.05$ was present.

\section{Results}

In these investigations it was necessary to quantitate and compare the effect of the shorter chain-length (predominately 8:0 and 10:0) saturated fatty acids in MCT with those of the longer chain-length (predominately 12:0 and 14:0) saturated fatty acids in HCO under circumstances where the dietary cholesterol content was varied systematically over the range commonly encountered in human diets. In this manner it was possible to define the metabolic differences that fatty acid chain-length imposes on LDL metabolism when these two triacylglycerols were fed together with a diet that was either very low or moderately high in cholesterol content.
The first study, summarized in Table I, characterized several parameters of sterol metabolism in the male hamsters fed diets containing $20 \% \mathrm{MCT}$ or $\mathrm{HCO}$ along with either $0 \%$ or $0.12 \%$ added dietary cholesterol. After $30 \mathrm{~d}$ of access to the six different diets, the mean animal weights were slightly elevated in the animals eating MCT and HCO. While cholesterol feeding did not effect mean animal weights, the average weights of the liver were consistently higher when cholesterol was present in the diet than when it was absence, as is apparent in column 4.

In the absence of dietary cholesterol, there was essentially no effect of triacylglycerol feeding on the levels of free and esterified cholesterol in the liver (columns 5 and 6). However, when $0.12 \%$ cholesterol was added to the diet, the cholesteryl ester content rose 66 -fold, from 0.3 to $19.8 \mathrm{mg} / \mathrm{g}$, but this increase was markedly blunted by the simultaneous feeding of MCT $(6.0 \mathrm{mg} / \mathrm{g})$ and, particularly, $\mathrm{HCO}(2.5 \mathrm{mg} / \mathrm{g})$. Again, the concentration of free cholesterol in the liver was essentially unaffected by triacylglycerol feeding. Finally, in the absence of dietary cholesterol MCT had no effect on the rate of hepatic cholesterol synthesis while HCO feeding essentially doubled this rate (column 7). However, in the presence of added dietary cholesterol, hepatic sterol synthesis was markedly suppressed.

There were also marked differences in the effect of these two saturated triacylglycerols on plasma LDL levels, as shown in Fig. 1. In the absence of dietary cholesterol, feeding $20 \%$ triacylglycerol had only a slight effect on the mean plasma LDL-cholesterol concentration which increased from 30 $\mathrm{mg} / \mathrm{dl}$ to $34 \mathrm{mg} / \mathrm{dl}$ with MCT feeding and to $51 \mathrm{mg} / \mathrm{dl}$ with the intake of HCO. The addition of $0.12 \%$ cholesterol alone raised the plasma LDL-cholesterol concentration to $89 \mathrm{mg} / \mathrm{dl}$ and the further addition of HCO raised this level to $191 \mathrm{mg} / \mathrm{dl}$ while, in contrast, the addition of MCT had no effect on the plasma LDL level beyond that seen with the addition of cholesterol alone. Thus, the addition of both $0.12 \%$ cholesterol and $20 \%$ HCO to the diet of these animals raised the plasma LDL-cholesterol concentration over sixfold under circumstances where there was no significant change in the concentration of cholesterol carried in the higher density lipoproteins. The addition of

Table I. Effects of Dietary Cholesterol and Saturated Triacylglycerols on Free and Esterified Hepatic Cholesterol and on Hepatic Cholesterol Synthesis

\begin{tabular}{|c|c|c|c|c|c|c|c|c|}
\hline \multicolumn{2}{|c|}{ Lipids added to control diet } & \multicolumn{2}{|c|}{ Food intake } & \multicolumn{2}{|c|}{ Final weights } & \multicolumn{2}{|c|}{ Hepatic cholesterol } & \multirow{2}{*}{$\begin{array}{c}\text { Hepatic } \\
\text { cholesterol } \\
\text { synthesis }\end{array}$} \\
\hline Cholesterol & Triacylglycerol & Amount & Gross energy & Animal & Liver & Free & Esterified & \\
\hline$\%$ & & $g / d$ & $k \mathrm{call} / \mathrm{d}$ & $g$ & $g$ & $m g / g$ & $m g / g$ & $n m o l / h$ per $g$ \\
\hline 0.00 & None & $12.0 \pm 0.6$ & 52.8 & $153 \pm 9$ & $6.6 \pm 0.4$ & $1.5 \pm 0.1$ & $0.3 \pm 0.1$ & $59 \pm 18$ \\
\hline 0.00 & MCT & $11.8 \pm 0.5$ & 60.4 & $164 \pm 8$ & $7.0 \pm 0.3$ & $1.9 \pm 0.1$ & $0.4 \pm 0.1$ & $59 \pm 16$ \\
\hline 0.00 & $\mathrm{HCO}$ & $8.8 \pm 0.4$ & 46.8 & $175 \pm 6$ & $7.3 \pm 0.4$ & $1.6 \pm 0.1$ & $0.3 \pm 0.1$ & $118 \pm 33$ \\
\hline 0.12 & None & ND & & $150 \pm 5$ & $7.6 \pm 0.4$ & $2.6 \pm 0.2^{*}$ & $19.8 \pm 3.0^{*}$ & $11 \pm 1^{*}$ \\
\hline 0.12 & MCT & $11.2 \pm 0.6$ & 57.3 & $155 \pm 5$ & $8.9 \pm 0.5$ & $2.5 \pm 0.1^{*}$ & $6.0 \pm 2.0^{* \pm}$ & $13 \pm 1^{*}$ \\
\hline 0.12 & $\mathrm{HCO}$ & $9.0 \pm 0.3$ & 47.9 & $175 \pm 6$ & $8.6 \pm 0.6$ & $2.6 \pm 0.2^{*}$ & $2.5 \pm 0.2^{* \ddagger}$ & $15 \pm 3^{*}$ \\
\hline
\end{tabular}

Diets were enriched with either no cholesterol or $0.12 \%$ (wt/wt) cholesterol and with either no triacylglycerol or $20 \%$ (wt/wt) medium chainlength triglyceride (MCT) or hydrogenated coconut oil (HCO). After $30 \mathrm{~d}$ on these diets the rates of hepatic cholesterol synthesis were measured in vivo and the concentration of free and esterified cholesterol in the liver was quantitated. Each value represents the mean \pm 1 SEM for data obtained in six animals. In several groups of these data there was both a main effect of cholesterol and an interaction of triacylglycerol with cholesterol $(P<0.05)$. Significant effects of cholesterol are indicated by an *, while significant effects of triacylglycerol at any level of dietary cholesterol are designated by $\mathrm{a}^{\ddagger}(P<0.01)$. 


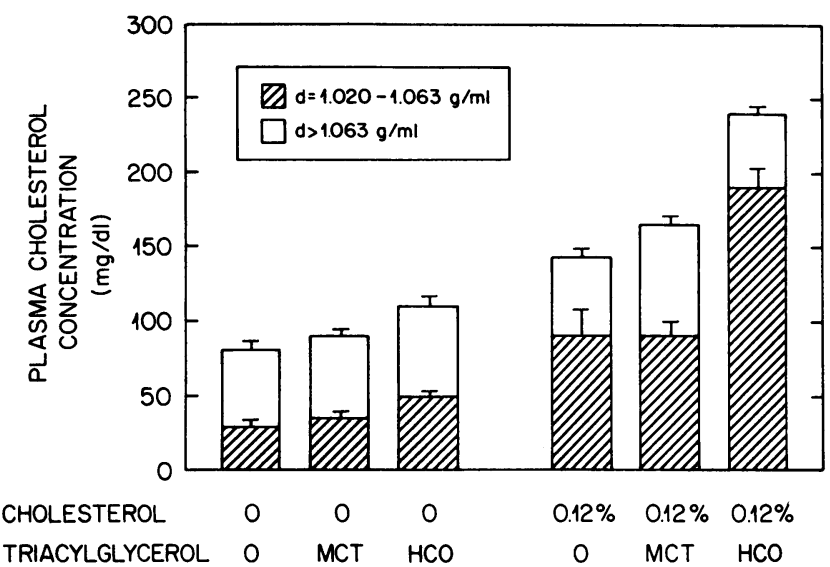

Figure 1. Plasma low and high density lipoprotein-cholesterol concentrations in hamsters fed different diets. These measurements were made on the plasma of the animals described in Table I that were fed diets containing either no added cholesterol or $0.12 \%$ cholesterol in combination with either no triacylglycerol or $20 \%$ medium chainlength triglyceride (MCT) or hydrogenated coconut oil (HCO). Mean values \pm 1 SEM are shown for six animals in each group.

triacylglycerol alone to the diet also had little effect on the cholesterol concentration in the lipoproteins with a density $<1.020 \mathrm{~g} / \mathrm{ml}(16,29$, and $26 \mathrm{mg} / \mathrm{dl}$, respectively, in the control, MCT-, and HCO-fed groups). When cholesterol was added to these diets these same three groups had cholesterol concentrations in these very low density lipoproteins of 74, 92 , and $324 \mathrm{mg} / \mathrm{dl}$, respectively.

In order to define the processes responsible for these marked dietary effects on LDL-cholesterol concentrations detailed measurements were next undertaken of the parameters of LDL metabolism that lead to changes in the steady-state LDL-cholesterol levels. As summarized in Table II, the clear- ance of LDL into various tissues of the body and by the whole animal was measured in nine groups of hamsters fed diets containing $0 \%, 0.06 \%$, and $0.12 \%$ of added cholesterol in combination with either $0 \%$ or $20 \%$ MCT or HCO. As shown in column 6 of this table, these diets had marked effects on the turnover of LDL-cholesterol in the whole animal. The addition of $0.06 \%$ and $0.12 \%$ cholesterol alone to the diet reduced LDL-cholesterol clearance from the mean control value of 1,106 to 749 and $568 \mu \mathrm{l} / \mathrm{h}$, respectively. In the absence of added cholesterol, feeding HCO had no effect on LDL clearance by the whole animal $(1,033 \mu \mathrm{l} / \mathrm{h})$ : however, when cholesterol was present in the diet, this saturated longer chain-length triacylglycerol caused a marked decrease in clearance at both the $0.06 \%$ (432 vs. $749 \mu \mathrm{l} / \mathrm{h}$ ) and $0.12 \%$ (258 vs. $568 \mu \mathrm{l} / \mathrm{h}$ ) levels. In contrast, the mean clearance rates of LDL in the animals fed MCT were consistently higher than the mean values of the appropriate controls at all three levels of cholesterol feeding. Thus, in the extreme case, LDL clearance fell from a value of $1,106 \mu \mathrm{l} / \mathrm{h}$ in the animals on no added cholesterol or triacylglycerol to $258 \mu \mathrm{l} / \mathrm{h}$ in animals given $0.12 \%$ cholesterol and $20 \% \mathrm{HCO}$. These changes in clearance rates correspond to a decrease in the fractional catabolic rate of LDL from $\sim 4.5$ pools/d to only 0.87 pools/d.

The organs responsible for this marked decrease in LDL turnover are also evident in Table II. In the animals receiving neither cholesterol nor triacylglycerol, LDL uptake into the liver $(794 \mu \mathrm{l} / \mathrm{h})$ and small bowel $(59.7 \mu \mathrm{l} / \mathrm{h})$ together accounted for nearly $80 \%$ of the whole animal clearance rate $(1,106 \mu \mathrm{l} / \mathrm{h})$. Furthermore, only the liver manifested the striking changes in clearance rates that were brought about by the diet manipulations. Again, cholesterol feeding alone decreased hepatic LDL clearance from 794 to $494(0.06 \%$ level $)$ and $352 \mu \mathrm{l} / \mathrm{h}(0.12 \%$ level). Furthermore, in the absence of cholesterol, feeding triacylglycerol had no suppressive effect upon hepatic LDL clearance. In the presence of cholesterol, however, HCO suppressed LDL uptake from $794 \mu \mathrm{l} / \mathrm{h}$ to $149 \mu \mathrm{l} / \mathrm{h}(0.12 \%$ level $)$ whereas,

Table II. Effects of Dietary Cholesterol and Saturated Triacylglycerols on LDL-Cholesterol Clearance in Several Major Tissues and in the Whole Animal

\begin{tabular}{|c|c|c|c|c|c|c|c|}
\hline \multicolumn{2}{|c|}{ Lipids added to control diet } & \multicolumn{6}{|c|}{ Tissue LDL-cholesterol clearance } \\
\hline Cholesterol & Triacylglycerol & Liver & Small bowel & Adrenal & Spleen & Kidney & Whole animal \\
\hline$\%$ & & \multicolumn{6}{|c|}{$\mu l / h$ per organ or animal } \\
\hline 0.00 & None & $794 \pm 41$ & $59.7 \pm 5.4$ & $4.8 \pm 0.2$ & $6.7 \pm 1.3$ & $15.8 \pm 2.6$ & $1,106 \pm 59$ \\
\hline 0.00 & MCT & $967 \pm 88$ & $68.0 \pm 6.9$ & $4.7 \pm 1.5$ & $9.2 \pm 0.2$ & $10.4 \pm 1.9$ & $1,295 \pm 122$ \\
\hline 0.00 & $\mathrm{HCO}$ & $786 \pm 164$ & $60.6 \pm 5.7$ & $2.9 \pm 0.4$ & $6.6 \pm 0.7$ & $15.2 \pm 5.3$ & $1,033 \pm 194$ \\
\hline 0.06 & None & $494 \pm 83$ & $48.1 \pm 4.2$ & $4.2 \pm 0.2$ & $7.1 \pm 0.5$ & $7.8 \pm 0.4$ & $749 \pm 120$ \\
\hline 0.06 & MCT & $731 \pm 121$ & $47.0 \pm 5.1$ & $4.9 \pm 0.4$ & $8.1 \pm 1.1$ & $9.1 \pm 1.4$ & $989 \pm 150$ \\
\hline 0.06 & $\mathrm{HCO}$ & $275 \pm 45^{*}$ & $38.2 \pm 4.2^{*}$ & $3.0 \pm 0.8$ & $6.4 \pm 0.6$ & $6.3 \pm 0.5$ & $432 \pm 56^{*}$ \\
\hline 0.12 & None & $352 \pm 29^{*}$ & $40.5 \pm 4.2^{*}$ & $3.4 \pm 0.5$ & $6.9 \pm 0.8$ & $7.0 \pm 0.5$ & $568 \pm 43^{*}$ \\
\hline 0.12 & MCT & $378 \pm 41^{*}$ & $40.7 \pm 4.1^{*}$ & $1.8 \pm 0.4$ & $7.6 \pm 1.6$ & $7.0 \pm 1.8$ & $590 \pm 60^{*}$ \\
\hline 0.12 & $\mathrm{HCO}$ & $149 \pm 30^{* \neq}$ & $23.6 \pm 4.5^{*}$ & $1.3 \pm 0.3$ & $4.6 \pm 0.9$ & $7.2 \pm 2.2$ & $258 \pm 40^{* \neq}$ \\
\hline
\end{tabular}

Diets were enriched with either no cholesterol or $0.06 \%$ or $0.12 \%$ cholesterol and with either no triacylglycerol or $20 \%$ medium chain-length triglyceride (MCT) or hydrogenated coconut oil (HCO). These diets were fed for $30 \mathrm{~d}$ at which time the rates of LDL transport out of the plasma into various tissues were measured. These rates are expressed as the microliter of plasma cleared of its LDL content per hour per whole organ or per whole animal. Each value represents the mean \pm 1 SEM for data obtained in six animals. In several groups of these data there was both a main effect of cholesterol and an interaction of triacylglycerol with cholesterol $(P<0.05)$. Significant effects of cholesterol are indicated by an *, while significant effects of triacylglycerol at any level of dietary cholesterol are designated by $\mathrm{a}^{\ddagger}(P<0.01)$. 
under the same dietary conditions, feeding MCT invariably increased the mean LDL-cholesterol clearance rate regardless of whether this triacylglycerol was fed alone ( $967 \mathrm{vs} .794 \mu \mathrm{l} / \mathrm{h}$ ) or with $0.06 \%$ (731 vs. $494 \mu \mathrm{l} / \mathrm{h}$ ) or $0.12 \%$ (378 vs. $352 \mu \mathrm{l} / \mathrm{h}$ ) cholesterol. It is also evident from these data that only a few of the other organs showed similar changes in clearance rates with these dietary manipulations and, further, these changes were not nearly so dramatic in either absolute or relative terms as those seen in the liver.

From these measurements it was next possible to determine how these dietary manipulations altered hepatic and whole animal LDL receptor activity and LDL-cholesterol production rates. The rate of hepatic LDL-cholesterol clearance (Table II, column 1) in each animal was multiplied by the concentration of plasma LDL-cholesterol in that same animal to give the absolute rate of LDL-cholesterol uptake $\left(J_{t}\right)$ by the liver. After normalizing these values to a constant animal weight of $100 \mathrm{~g}$, values were averaged and are shown for each of the dietary groups in column 1 of Table III. As is apparent, LDL-cholesterol uptake by both receptor-dependent and receptor-independent transport mechanisms averaged $129 \mu \mathrm{g} / \mathrm{h}$ in the liver of a $100-\mathrm{g}$ control hamster. The addition of cholesterol to the diet increased this value slightly $(152-155 \mu \mathrm{g} / \mathrm{h})$ while the addition of either MCT or HCO further enhanced hepatic LDL-cholesterol uptake, but only into the range of $176-199 \mu \mathrm{g} / \mathrm{h}$.

The second column of data in Table III show similar values for the absolute rates of uptake $\left(J_{t}\right)$ of LDL-cholesterol from the plasma space into all organs in the body, including the liver. These values were determined directly in each animal by combining the uptake rates measured in the liver and other organs shown in Table II with uptake rates also determined in the remaining carcass. The third column of data in Table III gives the percentage of total LDL-cholesterol removed from the plasma in the whole animal that was taken up by the liver.
Thus, the $100-\mathrm{g}$ animal fed neither cholesterol nor triacylglycerol removed $180 \mu \mathrm{g} / \mathrm{h}$ of LDL-cholesterol from the plasma and $72 \%$ of this transport took place into the liver. With cholesterol feeding alone, the amount of LDL-cholesterol removed from the plasma increased to $235 \mu \mathrm{g} / \mathrm{h}(0.06 \%$ level $)$ and $244 \mu \mathrm{g} / \mathrm{h}(0.12 \%$ level), and the importance of the liver to this transport process decreased to $66 \%$ and $62 \%$, respectively. The addition of either of the triacylglycerols to the diet further increased the amount of LDL-cholesterol flowing through the plasma compartment so that in the extreme case where $0.12 \%$ cholesterol and $20 \% \mathrm{HCO}$ were fed, $330 \mu \mathrm{g} / \mathrm{h}$ of LDL-cholesterol was being removed from the plasma but only $58 \%$ of this occurred in the liver. It is noteworthy that in contrast to the differential effects of MCT and HCO on such parameters as hepatic cholesteryl ester levels, plasma LDL-cholesterol concentrations and rates of hepatic sterol synthesis, these two triacylglycerols had similar effects on increasing the amount of LDL-cholesterol flux through the plasma compartment. It is also evident from these studies that cholesterol $(0.12 \%$ level) and $\mathrm{HCO}$ feeding resulted in an increase in the absolute rate of LDL-cholesterol removal from the plasma of $150 \mu \mathrm{g} / \mathrm{h}$ but only $62 \mu \mathrm{g} / \mathrm{h}$ of this increment was accounted for by increased uptake into the liver. Thus, in the face of a high-cholesterol, high-triacylglycerol diet, the peripheral, extra-hepatic organs were forced to take up $\sim 140 \mu \mathrm{g} / \mathrm{h}$ of LDL-cholesterol compared to the $50 \mu \mathrm{g} / \mathrm{h}$ these tissues removed from the plasma in animals fed the low-fat, control diet.

When these absolute rates of LDL-cholesterol transport were compared to the kinetic curves describing receptor-dependent and receptor-independent LDL-cholesterol transport in the liver and whole animal it was next possible to determine how these dietary manipulations altered hepatic and whole animal receptor activity $\left(* J^{\mathrm{m}}\right)$. The solid curve shown in Fig. 2 represents the expected rate of LDL-cholesterol transport into the liver $\left(J_{t}\right)$ by both receptor-dependent and receptor-inde-

Table III. Effects of Dietary Cholesterol and Saturated Triacylglycerols on LDL-Cholesterol Uptake into the Liver and Whole Animal and on Relative Hepatic LDL-Receptor Activity and LDL-Cholesterol Production Rates

\begin{tabular}{|c|c|c|c|c|c|c|c|}
\hline \multicolumn{2}{|c|}{ Lipids added to control diet } & \multicolumn{2}{|c|}{$\begin{array}{c}\text { Total LDL-cholesterol uptake } \\
\left(\mathbf{( J}_{\mathbf{l}}\right)\end{array}$} & \multirow{2}{*}{$\begin{array}{c}\text { Hepatic contribution } \\
\text { to whole animal } \\
\text { LDL-cholesterol } \\
\text { uptake }\end{array}$} & \multirow{2}{*}{$\begin{array}{l}\text { Relative hepatic } \\
\text { LDL receptor } \\
\text { activity }\left(* J^{m}\right)\end{array}$} & \multirow{2}{*}{$\begin{array}{l}\text { Proportion of hepatic } \\
\text { LDL-cholesterol } \\
\text { uptake that is } \\
\text { receptor-dependent }\end{array}$} & \multirow{2}{*}{$\begin{array}{c}\text { Relative } \\
\text { LDL-cholesterol } \\
\text { production rate } \\
\qquad\left(J_{t}\right)\end{array}$} \\
\hline Cholesterol & Triacylglycerol & Liver & Whole animal & & & & \\
\hline \multicolumn{2}{|c|}{$\%$} & \multicolumn{2}{|c|}{$\mu g / h$ per liver or animal } & $\%$ & $\%$ & $\%$ & $\%$ \\
\hline 0.00 & None & $129 \pm 7$ & $180 \pm 10$ & 72 & 100 & 95 & 100 \\
\hline 0.00 & MCT & $199 \pm 18$ & $266 \pm 25$ & 75 & 113 & 95 & 143 \\
\hline 0.00 & $\mathrm{HCO}$ & $193 \pm 41$ & $254 \pm 47$ & 76 & 93 & 94 & 136 \\
\hline 0.06 & None & $155 \pm 26$ & $235 \pm 37$ & 66 & 72 & 92 & 126 \\
\hline 0.06 & MCT & $190 \pm 32$ & $257 \pm 37$ & 74 & 92 & 94 & 137 \\
\hline 0.06 & $\mathrm{HCO}$ & $176 \pm 29$ & $277 \pm 36$ & 64 & 40 & 81 & 149 \\
\hline 0.12 & None & $152 \pm 13$ & $244 \pm 19$ & 62 & 48 & 87 & 131 \\
\hline 0.12 & MCT & $183 \pm 20$ & $285 \pm 29$ & 64 & 56 & 88 & 152 \\
\hline 0.12 & $\mathrm{HCO}$ & $191 \pm 39$ & $330 \pm 50$ & 58 & 30 & 70 & 182 \\
\hline
\end{tabular}

Diets were enriched with either no cholesterol or $0.06 \%$ or $0.12 \%$ cholesterol and with either no triacylglycerol or $20 \%$ medium chain-length triglyceride (MCT) or hydrogenated coconut oil (HCO). These diets were fed for $30 \mathrm{~d}$. Total LDL-cholesterol uptake $\left(J_{t}\right)$ represents the rate of both receptor-dependent $\left(J_{\mathrm{d}}\right)$ and receptor-independent $\left(J_{\mathrm{i}}\right)$ LDL-cholesterol uptake by the liver and by all tissues in the whole animal. These values were calculated from the clearance data shown in Table II and have been normalized to a constant animal weight of $100 \mathrm{~g}$. The values for hepatic receptor activity $\left(* J^{\mathrm{m}}\right)$ and LDL-cholesterol production rates shown in columns 4 and 6 , respectively, are given relative to the control group of animals that received neither cholesterol nor triacylglycerol. There were no main effects or interactions in columns $l$ and $2(P<0.05)$. 


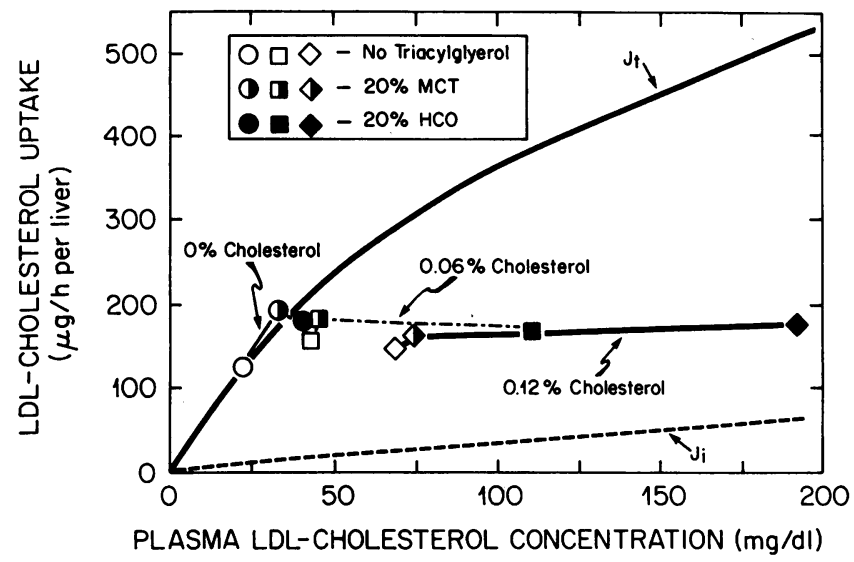

Figure 2. The rate of hepatic LDL-cholesterol uptake as a function of the plasma LDL-cholesterol concentration in hamsters fed different amounts of cholesterol and triacylglycerol. The two curves labeled $J_{t}$ and $J_{i}$ represent, respectively, the expected rates of total LDL-cholesterol uptake and the receptor-independent component of this uptake at any plasma LDL-cholesterol concentration in the liver of control animals fed no additional cholesterol or triacylglycerol. These two curves were determined in control animals and are described by the following parameter values (all normalized to a $100-\mathrm{g}$ animal weight): $* J^{\mathrm{m}}$ of $708 \mu \mathrm{g} / \mathrm{h}, * K_{\mathrm{m}}$ of $109 \mathrm{mg} / \mathrm{dl}$ and $* \mathrm{P}$ of $0.30 \mu \mathrm{g} / \mathrm{h}$ per $\mathrm{mg} / \mathrm{dl}$. The mean absolute rates of LDL-cholesterol uptake, also normalized to a 100-g body wt, from Table III are plotted on these curves. The relative reduction in receptor activity $\left(* J^{\mathrm{m}}\right)$ can be derived from this plot and is listed for each experimental group in column 4 of Table III. The lines shown in this diagram simply connect the groups of animals that were given diets containing $0,0.06$, or $0.12 \%$ of added cholesterol.

pendent mechanisms while the dashed line illustrates the magnitude of the receptor-independent component $\left(J_{i}\right)$. These curves were constructed in control animals fed the diet containing neither cholesterol nor triacylglycerol and were generated from equation 1 in Methods after determining that the LDL-receptor activity in the liver of these animals was capable of giving a maximal uptake rate $\left(* J^{\mathrm{m}}\right)$ of $708 \mu \mathrm{g} / \mathrm{h}$ and the receptor-independent component was described by $\mathrm{a} * \mathrm{P}$ value of $0.30 \mu \mathrm{g} / \mathrm{h}$ per $\mathrm{mg} / \mathrm{dl}$. The control animals in this study that received neither cholesterol nor triacylglycerol are plotted as the open circle in Fig. 2 and manifested an LDL-cholesterol uptake rate of $129 \mu \mathrm{g} / \mathrm{h}$ at a mean plasma LDL-cholesterol concentration of $23 \mathrm{mg} / \mathrm{dl}$. Nearly $123 \mu \mathrm{g} / \mathrm{h}$, or $95 \%$, of this uptake was receptor dependent. The total LDL receptor activity present in the livers of this group of animals was assigned a value of $100 \%$ in column 4 of Table III while the proportion of hepatic LDL-cholesterol uptake that was receptor-dependent is shown in column 5 . It should be noted that the rate of hepatic receptor-dependent LDL-cholesterol transport $\left(J_{d}\right)$ in these animals $(123 \mu \mathrm{g} / \mathrm{h})$ is well below the maximal rate $\left(* J^{\mathrm{m}}\right)$ of $708 \mu \mathrm{g} / \mathrm{h}$ that could have been achieved if the receptor-dependent process were fully saturated. As noted before $(4,7)$, most animals, including man, normally function by using only a fraction of their available LDL receptor activity.

When mean values for the other eight diet groups were superimposed on this curve, a very important characteristic of the regulation of hepatic LDL transport became apparent. As is evident in Fig. 2, regardless of what was fed in the diet, the liver regulated its level of receptor-dependent LDL transport to maintain the rate of uptake of this lipoprotein fraction re- markably constant at $\sim 150-190 \mu \mathrm{g} / \mathrm{h}$ even though the plasma LDL-cholesterol concentration varied over an eightfold range. It is also clear that there were striking differences in the magnitude of regulation necessary to maintain this homeostasis in the face of the different dietary lipids. Cholesterol feeding alone, for example, reduced hepatic LDL receptor activity to $72 \%(0.06 \%$ level) and $48 \%(0.12 \%$ level $)$ of the control value. The addition of HCO to these diets augmented the cholesterol effect and further reduced receptor activity. In contrast, at any level of cholesterol feeding, MCT consistently increased receptor-dependent LDL transport. Thus, relative hepatic receptor activity with MCT and HCO feeding, respectively, equaled $113 \%$ and $93 \%$ of control when no cholesterol was added to the diet, $92 \%$ and $40 \%$ when $0.06 \%$ cholesterol was fed and $56 \%$ and $30 \%$ when $0.12 \%$ cholesterol was in the diet (column 4). Hence, when compared to the appropriate control group, HCO always augmented the suppressive effect of dietary cholesterol on hepatic receptor activity while MCT consistently reduced this effect. Finally, with these reductions in receptor activity, there was a corresponding decrease in the importance of the receptor-dependent process for LDL-cholesterol uptake by the liver (column 5). Thus, in the extreme case shown in Fig. 2, where cholesterol (0.12\% level) and HCO feeding raised the plasma LDL-cholesterol concentration to $190 \mathrm{mg} / \mathrm{dl}$, the expected rate of hepatic LDL-cholesterol uptake would have been $\sim 500 \mu \mathrm{g} / \mathrm{h}$. However, because of a $70 \%$ reduction in LDL receptor activity, the uptake rate was kept constant at $191 \mu \mathrm{g} / \mathrm{h}$ and $30 \%$ of the uptake was now by way of the receptor-independent process (column 5).

The last column of data in Table III shows the relative rates of LDL production in these same dietary groups. In the control animals fed no added lipids, the production rate equaled 180 $\mu \mathrm{g}$ of LDL-cholesterol per $\mathrm{h}$. This value was set equal to $100 \%$ and the values in the other dietary groups are given relative to this control value. It is clear that LDL production rates were increased by feeding cholesterol and either triacylglycerol. However, there was a consistent relationship such that the increment in the production rate was greatest with $\mathrm{HCO}$, intermediate with MCT and smallest with cholesterol alone. Thus, the highest LDL-cholesterol production rate of $182 \%$ of control was seen in the animals fed both $\mathrm{HCO}$ and cholesterol ( $0.12 \%$ level).

Finally, the effects of these diets on LDL-transport into the peripheral, extrahepatic organs is illustrated in Fig. 3. In A, the rates of LDL-cholesterol removal from the plasma $\left(J_{t}\right)$ in the whole animal found in each diet group (Table III) are compared to the rates of transport that would have occurred in control animals over the same range of plasma LDL-cholesterol concentrations. As is apparent, the rates of LDL-cholesterol uptake were significantly suppressed by feeding cholesterol and the two triacylglycerols, although the uptake rates clearly increased slightly (from $\sim 230$ to $330 \mu \mathrm{g} / \mathrm{h}$ ) as the plasma LDL-cholesterol concentration increased to nearly 200 $\mathrm{mg} / \mathrm{dl}$. As already noted, however, uptake into the liver was essentially constant (B) because of the marked suppression of receptor-dependent LDL transport that was induced in this organ by these dietary lipids. It was not surprising, therefore, that the increased rate of LDL-cholesterol uptake found in the whole animal (A) was fully accounted for by increased LDLcholesterol uptake in the extrahepatic tissues (C). Thus, in the face of the diet-induced increase in LDL-cholesterol production, the extrahepatic tissues took up significantly greater 


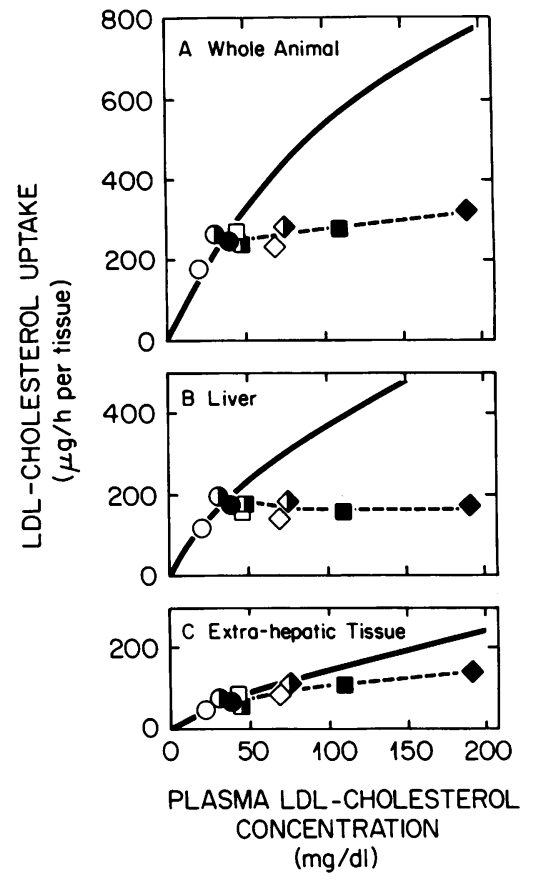

$130 \mu \mathrm{g} / \mathrm{h}, * K_{\mathrm{m}}$ of $100 \mathrm{mg} / \mathrm{dl}$ and $* \mathrm{P}$ of $0.78 \mu \mathrm{g} / \mathrm{h}$ per mg/dl. The parameter values for the liver are the same as given in Fig. 2 . The points show the mean values for the nine different feeding groups as identified in Fig. 2.

quantities of LDL-cholesterol. This result is consistent with the fact that the majority of receptor-independent LDL transport found in the whole animal is localized in the extrahepatic tissues $(7,12)$ and, further, that the rate of such uptake increases linearly with increases in the plasma LDL-cholesterol concentration $(7,9)$.

\section{Discussion}

These studies provide a broad outline of the events that lead to elevation of the plasma LDL-cholesterol level in the hamster. With the intake of cholesterol and saturated triacylglycerol there is a marked increase in the delivery of LDL-cholesterol into the plasma space and a reduction in the level of receptordependent LDL uptake by the liver. With this partial loss of hepatic clearance and the increased production rate, there is a progressive rise in the plasma LDL-cholesterol concentration until the velocity of the remaining receptor-dependent and receptor-independent uptake activities in the various tissues achieve a rate of LDL-cholesterol removal that equals the rate of LDL-cholesterol introduction into the plasma space. Once this new steady-state is achieved, there is a significant elevation of the plasma LDL-cholesterol concentration and an increase in the relative importance of the extra-hepatic tissues as sites for LDL degradation (Table III). These changes, in turn, are manifest kinetically as a reduced rate of plasma LDL-cholesterol clearance (Table II) or as a lower fractional catabolic rate of LDL in the whole animal.

In addition to these broad concepts, however, these studies also provide a detailed description of the physiological events that lead to these changes in the hamster, and illustrate signifcant differences in the effects of saturated fatty acids of different chain length on these events. The first, and most striking, of these differences is seen with the regulation of receptor-de- pendent LDL-cholesterol transport by the liver. When cholesterol alone is added to the diet there is modest suppression of hepatic receptor activity, which is dependent upon the level of cholesterol fed (Table III). In contrast, feeding large quantities of either MCT or HCO alone results in virtually no change in hepatic receptor-dependent LDL uptake. However, as has been reported before (20), when cholesterol is present in the diet the intake of longer chain-length fatty acids augments the suppressive effect of dietary sterols and leads to even greater suppression of receptor activity in the liver. Feeding identical amounts of the shorter chain-length fatty acids, on the other hand, has the opposite effect and actually partially restores receptor-dependent LDL transport in the liver (Table III). Thus, in the presence of dietary cholesterol, the chain-length of the saturated fatty acids markedly influences their effects on hepatic receptor activity.

The quantitative relationship between these dietary additions and receptor-dependent LDL uptake in the liver became evident in these studies only after direct measurements were made of the absolute rates of LDL-cholesterol transport into the liver in the different groups of animals. In hamsters receiving neither cholesterol nor triacylglycerol, $\sim 130 \mu \mathrm{g}$ of LDLcholesterol were taken up by the liver each hour. Under circumstances where various amounts of the different lipids were added to the diet, this rate of LDL-cholesterol uptake remained remarkably constant and in the range of 150 to 200 $\mu \mathrm{g} / \mathrm{h}$ (Fig. 2). It appeared that as various quantities of cholesterol and triacylglycerol were delivered to the liver, downregulation of receptor-dependent LDL uptake occurred to the degree necessary to maintain hepatic LDL-cholesterol uptake constant and just above control levels. Thus, this finding suggests that the liver alters its level of receptor activity in response to various dietary lipids so as to maintain a constant rate of LDL-cholesterol uptake from the plasma even though such adjustments may lead to detrimental elevations of the circulating plasma LDL-cholesterol concentration.

The second determinant of the plasma LDL-cholesterol concentration affected by dietary lipids is the rate of entry of LDL-cholesterol into the plasma. Feeding cholesterol alone results in modest increases in LDL-cholesterol production rates while feeding triacylglycerol alone has a somewhat greater effect (Table III). When both cholesterol and triacylglycerol are fed together there is a still greater increase in LDL-cholesterol production rates. Thus, unlike the effects of these lipids on hepatic LDL receptor activity, dietary cholesterol and both the shorter and longer chain-length triacylglycerols have similar effects and increase the rate of delivery of LDL-cholesterol into the plasma pool. These increases in LDL-cholesterol delivery primarily reflected the production of a particle relatively enriched with cholesterol, as reported in other species (29). However, these studies do not elucidate whether this increased delivery was associated with an increased rate of apolipoprotein B synthesis in the liver, an increased fractional conversion of very low density lipoproteins to LDL or, even, to an increase in the transfer of cholesterol from other lipoprotein fractions to LDL.

While the liver is of paramount importance to both receptor-dependent LDL clearance and LDL-cholesterol production, the remaining organs of the body can play a significant role in the turnover of LDL-cholesterol. With cholesterol and HCO feeding, for example, total LDL-cholesterol production increased from 180 to $330 \mu \mathrm{g} / \mathrm{h}$ (Table III). Since hepatic up- 
take under these circumstances became constant at $\sim 190$ $\mu \mathrm{g} / \mathrm{h}$, it follows that the excess LDL-cholesterol introduced into the plasma must have been cleared in the extrahepatic organs, as was also demonstrated in these studies by direct measurement (Fig. 3). Thus, the high-fat diets fed in these studies not only result in enhanced LDL-cholesterol production and downregulation of hepatic LDL receptor activity but, in addition, partially shift the burden of LDL clearance away from the liver to the extrahepatic organs.

With these measurements of the rates of whole animal LDL-cholesterol production and receptor-dependent LDLcholesterol transport, it is now possible to understand in quantitative terms how these two parameters of LDL metabolism interact to alter the steady-state level of plasma LDLcholesterol. This interaction is best illustrated by plotting the experimental data from this study upon the theoretical curves that describe how the plasma LDL-cholesterol level changes given any alteration in the production rate or receptor activity. The curves describing these relationships can be calculated using Eq. 2 in Methods and are shown as the heavy lines in Fig. 4. In the control hamsters fed neither cholesterol nor triacylglycerol the LDL-cholesterol production rate $\left(J_{t}\right)$ is $180 \mu \mathrm{g} / \mathrm{h}$ and receptor activity $\left(* J^{\mathrm{m}}\right)$ in the whole animal equals 838 $\mu \mathrm{g} / \mathrm{h}$ : these two values are set equal to $100 \%$ for the relative LDL-cholesterol production rate and LDL receptor activity shown in Fig. 4. The other two variables in the equation, $* K_{\mathrm{m}}$ and $* P$, have been shown to be relatively unaffected by lipid feeding and have been kept constant at $100 \mathrm{mg} / \mathrm{dl}$ and 1.08 $\mu \mathrm{g} / \mathrm{h}$ per $\mathrm{mg} / \mathrm{dl}$, respectively, for the purposes of these calculations.

Fig. $4 A$ shows the effect of adding either HCO or MCT alone to the diet. The open circle represents the control animals receiving neither cholesterol nor triacylglycerol: these animals had a whole-body receptor activity and production rate set equal to $100 \%$ and a steady-state plasma LDL-choles-

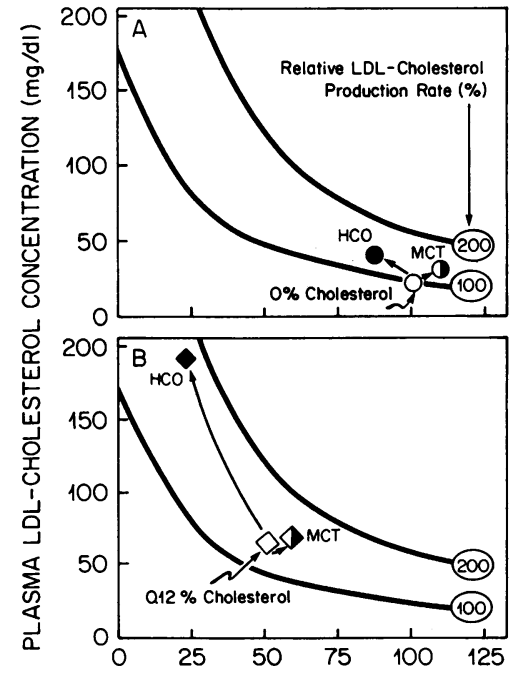

RELATIVE LDL RECEPTOR ACTIVITY (\%)
Figure 4. The plasma LDL-cholesterol concentration as a function of the relative receptor activity $\left(* J^{\mathrm{m}}\right)$ and production rate $\left(J_{t}\right)$ in hamsters fed different amounts of cholesterol and triacylglycerol. The solid curves show the expected values for the LDL-cholesterol concentration under circumstances where LDL receptor activity has been systematically varied from 0 to $125 \%$ of the control value and where the LDL-cholesterol production rate has been set equal to ei-

ther 100 or $200 \%$ of the control value. These curves were calculated as described in Methods. The symbols represent the same diet groups defined in Fig. 2. $A$ illustrates what happens when either HCO or MCT is fed to the male hamsters in the absence of added dietary cholesterol. $(B)$ The effect of feeding these two triacylglycerols in the presence of $0.12 \%$ of added dietary cholesterol. terol concentration of $23 \mathrm{mg} / \mathrm{dl}$. The addition of $\mathrm{HCO}$ to the diet caused a small decrease in receptor activity coupled with a $36 \%$ increase in the production rate so that the plasma LDLcholesterol concentration rose slightly to $41 \mathrm{mg} / \mathrm{dl}$. Feeding MCT caused a similar increase in production but because of a slight increase in receptor activity the plasma LDL-cholesterol concentration rose to only $34 \mathrm{mg} / \mathrm{dl}$. These differences became much more striking when cholesterol was added to the diet, as shown in B. The addition of $0.12 \%$ cholesterol alone elevated the plasma LDL-cholesterol concentration to $68 \mathrm{mg} / \mathrm{dl}$ and it is apparent that this occurred because of loss of $50 \%$ of the whole-body receptor activity and a small increase in the production rate. The addition of MCT to this diet slightly restored receptor activity but caused a greater increase in the production rate so that the plasma LDL-cholesterol concentration increased slightly to $74 \mathrm{mg} / \mathrm{dl}$. With the addition of the longer chain-length triacylglycerol, however, there was both a further loss of receptor activity and a greater increase in the production rate so that the plasma LDL-cholesterol concentration increased markedly to $190 \mathrm{mg} / \mathrm{dl}$.

This graphic presentation emphasizes the potential errors that are inherent in attempting to interpret changes in plasma LDL-cholesterol concentration in terms of a single parameter such as LDL receptor activity. As shown in these studies with MCT feeding, and as is particularly true for unsaturated fatty acids $(19,20)$, even though a particular manipulation may increase LDL receptor activity the plasma LDL-cholesterol concentration may increase, remain unchanged or decrease depending upon how that manipulation also alters the production rate. Clearly one can make no prediction concerning the direction or magnitude of change in the plasma LDL-cholesterol level based upon a single parameter such as the production rate $\left(J_{\mathrm{t}}\right)$, receptor activity $\left(* J^{\mathrm{m}}\right)$, receptor affinity $\left(* K_{\mathrm{m}}\right)$ or receptor-independent transport $(* \mathrm{P})$. Such predictions require knowledge of all four parameters.

While these measurements provide detailed information on the physiological changes in LDL metabolism that occur with lipid feeding, the cellular signals that bring about these changes are less clear. When cholesterol alone was fed there was suppression of hepatic receptor-dependent LDL transport (Table III), inhibition of cholesterol synthesis and an increase in the cholesteryl ester content of the liver from 0.3 to 19.8 $\mathrm{mg} / \mathrm{dl}$ (Table I). These findings are similar to those that occur in various isolated cells $(30,31)$ and are consistent with the view that the liver cell has somehow sensed an expanded pool of cholesterol and so has suppressed further synthesis and uptake of cholesterol while storing excess amounts of sterol in an inert ester pool. However, regulation of these processes must be more complex than this model would suggest since it has been shown that, in vivo, receptor-dependent $L D L$ transport often remains constant under circumstances where there are marked changes in the rates of synthesis and ester formation $(11,20,32)$. Furthermore, in the present studies the addition of the longer chain-length fatty acids to the cholesterol-containing diet led to further suppression of receptor activity but, at the same time, was associated with a doubling of the rate of sterol synthesis and a marked reduction in the size of the cholesteryl ester pool to $2.5 \mathrm{mg} / \mathrm{g}$. Since one of the critical functions of cholesterol in the cell is maintenance of membrane fluidity within a very narrow range $(33,34)$, it is conceivable that the intracellular signal that regulates LDL receptor function is the relative rigidity of some critical membranous struc- 
ture. Inflow of excessive amounts of cholesterol and saturated long-chain length fatty acids from the diet would tend to increase membrane rigidity and, therefore, downregulate LDL receptor function. Presumably other regulatory mechanisms compartmentalized in other portions of the cell would independently regulate the rate of cholesterol synthesis on the endoplastic reticulum.

The shorter chain-length fatty acids contained in MCT have very different effects on receptor function. These fatty acids are known to be handled metabolically differently from the longer chain-length compounds. They are absorbed across the intestinal mucosa and carried directly to the liver in the portal circulation. There they are able to enter the mitochondrial compartment, without intervention of the carnitine transferase system, and are rapidly oxidized to acetyl CoA (35). This pool of activated acetate can then be used for the de novo synthesis of long chain-length fatty acids which, in the fed state, are esterified to triacylglycerol, incorporated into very low density lipoproteins and transported to the periphery for storage or oxidation. Thus, the very different effect of $\mathrm{HCO}$ and MCT on receptor activity seen in these studies may reflect the fact that the longer chain-length fatty acids are delivered to the liver as triacylglycerol carried in the chylomicron remnant, whereas the shorter compounds are taken up as free fatty acids and rapidly oxidized to acyl CoA. However, it is known that expansion of the intracellular pool of lipid, either by increased uptake or synthesis of fatty acids, is associated with increased hepatic triacylglycerol secretion in very low density lipoproteins (36-38). Thus, in contrast to the differential effects of $\mathrm{HCO}$ and MCT on intracellular regulatory events, both of these lipids would be expected to increase the secretion of very low density lipoproteins which, in turn, might account for the observed increases in LDL-cholesterol production. Whether this formulation is correct must await further investigations into the intracellular events associated with these significant physiological changes.

\section{Acknowledgments}

The authors wish to thank Rebecca Mayol-Sharp and Bryan Whitlock for their excellent technical assistance and Imogene Robison for preparation of this manuscript.

This work was supported by U. S. Public Health Service Research grants HL-09610, AM-19329, and AM-01221, a grant-in-aid from the American Heart Association and a grant from the Moss Heart Fund. During the time that these studies were carried out Dr. Woollett was also supported by U. S. Public Health Service Training Grant AM-07100.

\section{References}

1. Havel, R. J. 1986. Functional activities of hepatic lipoprotein receptors. Annu. Rev. Physiol. 48:119-134.

2. Meddings, J. B., and J. M. Dietschy. 1987. Regulation of plasma low density lipoprotein levels: new strategies for drug design. Prog. Clin. Biochem. Med. 5:1-24.

3. Meddings, J. B., and J. M. Dietschy. 1987. Low density lipoproteins and atherogenesis: implications for modification through alterations in diet and new drug designs. In Contributions of Chemistry to Health. Vol. 2. H. Machleidt, editor. VCH Verlagsgesellschaft $\mathrm{mbH}$, Frankfurt. 269-282.

4. Dietschy, J. M., D. K. Spady, and J. B. Meddings. 1988. A quantitative approach to low density lipoprotein metabolism in man and in various experimental animals. In Hyperlipidaemia and Atherosclerosis. K. E. Suckling and P. H. E. Groot, editors. Academic Press, Inc., Orlando, FL. 17-32.

5. Brown, M. S., and J. L. Goldstein. 1979. Receptor-mediated endocytosis: Insights from the lipoprotein receptor system. Proc. Natl. Acad. Sci. USA. 76:3330-3337.

6. Brown, M. S., and J. L. Goldstein. 1986. A receptor-mediated pathway for cholesterol homeostasis. Science (Wash. DC). 232:34-47.

7. Spady, D. K., J. B. Meddings, and J. M. Dietschy. 1986. Kinetic constants for receptor-dependent and receptor-independent low density lipoprotein transport in the tissues of the rat and hamster. J. Clin. Invest. 77:1474-1481.

8. Mahley, R. W., K. H. Weisgraber, G. W. Melchior, T. L. Innerarity, and K. S. Holcombe. 1980 . Inhibition of receptor-mediated clearance of lysine and arginine-modified lipoproteins from the plasma of rats and monkeys. Proc. Natl. Acad. Sci. USA. 77:225-229.

9. Spady, D. K., S. D. Turley, and J. M. Dietschy. 1985. Receptorindependent low density lipoprotein transport in the rat in vivo. Quantitation, characterization, and metabolic consequences. J. Clin. Invest. 76:1113-1122.

10. Pittman, R. C., T. E. Carew, A. D. Attie, J. L. Witztum, Y. Watanabe, and D. Steinberg. 1982. Receptor-dependent and receptorindependent degradation of low density lipoprotein in normal rabbits and in receptor-deficient mutant rabbits. J. Biol. Chem. 257:79948000.

11. Spady, D. K., S. D. Turley, and J. M. Dietschy. 1985. Rates of low density lipoprotein uptake and cholesterol synthesis are regulated independently in the liver. J. Lipid Res. 26:465-472.

12. Spady, D. K., M. Huettinger, D. W. Bilheimer, and J. M. Dietschy. 1987. Role of receptor-independent low density lipoprotein transport in the maintenance of tissue cholesterol balance in the normal and WHHL rabbit. J. Lipid Res. 28:32-41.

13. Spady, D. K., D. W. Bilheimer, and J. M. Dietschy. 1983. Rates of receptor-dependent and -independent low density lipoprotein uptake in the hamster. Proc. Natl. Acad. Sci. USA. 80:3499-3503.

14. Miller, N. E. 1984. Why does plasma low density lipoprotein concentration in adults increase with age? Lancet. i:263-267.

15. Grundy, S. M., G. L. Vega, and D. W. Bilheimer. 1985. Kinetic mechanisms determining variability in low density lipoprotein levels and rise with age. Arteriosclerosis. 5:623-630.

16. Stange, E. F., and J. M. Dietschy. 1984. Age-related decreases in tissue sterol acquisition are mediated by changes in cholesterol synthesis and not low density lipoprotein uptake in the rat. J. Lipid Res. 25:703-713.

17. Spady, D. K., and J. M. Dietschy. 1989. Interaction of aging and dietary fat in the regulation of low density lipoprotein transport in the hamster. J. Lipid Res. 30:559-569.

18. Kovanen, P. T., M. S. Brown, S. K. Basu, D. W. Bilheimer, and J. L. Goldstein. 1981. Saturation and suppression of hepatic lipoprotein receptors: a mechanism for the hypercholesterolemia of cholesterol-fed rabbits. Proc. Natl. Acad. Sci. USA. 78:1396-1400.

19. Spady, D. K., and J. M. Dietschy. 1985. Dietary saturated triacylglycerols suppress hepatic low density lipoprotein receptor activity in the hamster. Proc. Natl. Acad. Sci. USA. 82:4526-4530.

20. Spady, D. K., and J. M. Dietschy. 1988. Interaction of dietary cholesterol and triglycerides in the regulation of hepatic low density lipoprotein transport in the hamster. J. Clin. Invest. 81:300-309.

21. Tonks, D. B. 1967. The estimation of cholesterol in serum: A classification and critical review of methods. Clin. Biochem. 1:12-29.

22. Andersen, J. M., and J. M. Dietschy. 1978. Relative importance of high and low density lipoproteins in the regulation of cholesterol synthesis in the adrenal gland, ovary, and testis of the rat. J. Biol. Chem. 253:9024-9032.

23. Turley, S. D., J. M. Andersen, and J. M. Dietschy. 1981. Rates of sterol synthesis and uptake in the major organs of the rat in vivo. $J$. Lipid Res. 22:551-569.

24. Dietschy, J. M., and D. K. Spady. 1984. Measurement of rates 
of cholesterol synthesis using tritiated water. J. Lipid Res. 25:14691476.

25. Andersen, J. M., and J. M. Dietschy. 1979. Absolute rates of cholesterol synthesis in extrahepatic tissues measured with ${ }^{3} \mathrm{H}$-labeled water and ${ }^{14} \mathrm{C}$-labeled substrates. J. Lipid Res. 20:740-752.

26. Glass, C. K., R. C. Pittman, G. A. Keller, and D. Steinberg. 1983. Tissue sites of degradation of apoprotein A-I in the rat. J. Biol. Chem. 258:7161-7167.

27. Bilheimer, D. W., S. Eisenberg, and R. I. Levy. 1972. The metabolism of very low density lipoprotein proteins. I. Preliminary in vitro and in vivo observations. Biochim. Biophys. Acta. 260:212-221.

28. Snedecor, G. W., and W. G. Cochran. 1967. Statistical Methods. Iowa State University Press, Ames, IA.

29. Kushwaha, R. S., G. M. Barnwell, K. D. Carey, and H. C. McGill, Jr. 1986. Metabolism of apoprotein B in selectively bred baboons with low and high levels of low density lipoproteins. J. Lipid Res. 27:497-507.

30. Goldstein, J. L., M. K. Sobhani, J. R. Faust, and M. S. Brown. 1976. Heterozygous familial hypercholesterolemia: failure of normal allele to compensate for mutant allele at a regulated genetic locus. Cell. 9:195-203.

31. Bersot, T. P., and R. W. Mahley. 1976. Interaction of swine lipoproteins with the low density lipoprotein receptor in human fibroblasts. J. Biol. Chem. 251:2395-2398.
32. Stange, E. F., and J. M. Dietschy. 1983. Cholesterol synthesis and low density lipoprotein uptake are regulated independently in rat small intestinal epithelium. Proc. Natl. Acad. Sci. USA. 80:5739-5743.

33. Vessey, D. A., and D. Zakim. 1974. Membrane fluidity and the regulation of membrane-bound enzymes. Horizons Biochem. Biophys. 1:138-174.

34. Cooper, R. A. 1977. Abnormalities of cell-membrane fluidity in the pathogenesis of disease. N. Engl. J. Med. 297:371-377.

35. McGarry, J. D. 1986. Lipid metabolism I: Utilization and storage of energy in lipid form. In Textbook of Biochemistry with Clinical Correlations, 2nd ed. T. M. Devlin, editor. John Wiley \& Sons, New York. 355-389.

36. Heimberg, M., I. Weinstein, and M. Kohout. 1969. The effects of glucagon, dibutyryl cyclic adenosine 3 ',5'-monophosphate, and concentration of free fatty acid on hepatic lipid metabolism. J. Biol. Chem. 244:5131-5239.

37. Ide, T., and J. A. Ontko. 1981. Increased secretion of very low density lipoprotein triglyceride following inhibition of long chain fatty acid oxidation in isolated rat liver. J. Biol. Chem. 256:10247-10255.

38. Fukuda, N., M. J. Azain, and J. A. Ontko. 1982. Altered hepatic metabolism of free fatty acids underlying hypersecretion of very low density lipoproteins in the genetically obese Zucker rat. J. Biol. Chem. 257:14066-14072. 